\title{
Posttransplant acute limbic encephalitis
}

INSERM

\section{Source}

INSERM. (1999). Orphanet: an online rare disease and orphan drug data base.

Posttransplant acute limbic encephalitis. ORPHA:163921

Posttransplant acute limbic encephalitis is a rare, acquired, non-paraneoplastic limbic encephalitis disorder, that develops in the setting of treatment-related immunosuppression, typically after allogeneic hemapoietic stem cell transplantation, characterized by onset of confusion, headache, anterograde amnesia, seizures and/or loss of consciousness 2-6 weeks following transplantation. Bilateral, non-enhancing T2 hyperintensities in limbic structures are observed on magnetic resonance imag ing. Mild cerebrospinal fluid pleocytosis and syndrome of inappropriate antidiuretic hormone secretion may also be associated. 